\title{
Figuraciones, conservación y hegemonía en el proyecto de construcción de un camino en la Reserva de Biosfera Yabotí en San Pedro, Misiones - Argentina. Periodo desde el año 2012 hasta el año 2015*
}

\author{
Carla Antonella Cossi* ${ }^{* *}$ \\ Raimundo Elías Gómez ${ }^{* *}$
}

\section{Resumen}

El presente trabajo se propone describir, desde una perspectiva antropológica, la manera en que un conjunto de agentes ligados al turismo y a las áreas naturales protegidas -entre los que se encuentran organizaciones transnacionales gubernamentales y no gubernamentales, funcionarios políticos y empresarios- se disputan el capital político, simbólico y económico necesario para definir los límites de la conservación. Nos aproximamos, así, a las relaciones de fuerzas que generan las estrategias de conservación y turismo sustentable de los diferentes sectores involucrados con el proyecto de construcción de un camino provincial, al interior de la Reserva de Biosfera Yabotí y del Parque provincial Moconá, en San Pedro, Misiones-Argentina.

\footnotetext{
* Artículo recibido el 4 de Febrero de 2015. Aceptado el 5 de Junio de 2015.

** Gómez, Raimundo Elías (UNaM-CONICET).

Correo electrónico: Isgomez001@gmail.com

** Cossi, Carla Antonella: (UNaM-CONICET)

Correo electrónico: carlacossi@gmail.com
} 


\section{Palabras clave}

Turismo - conservación - áreas naturales protegidas.

\section{Abstract}

The present work propose to describe, from an anthropological perspective, the way that an ensemble of agents linked to tourism and protected natural areas- like transnational organizations, governmental organizations, politics workers and entrepreneurs- fight for the political, symbolic, and economic capital to define the limits of the conservation. We approach then to force relations, that produces the conservation strategies and sustainable tourism, of the different sectors involves with the construction project of the provincial road, in Yabotí Biosphere Reserve, and Moconá Provincial Park, in San Pedro, Misiones-Argentina.

\section{Keywords}

Tourism - conservation - natural protected areas.

\section{Introducción}

Un conjunto de interdependencias sociales actúan con fuerza sobre las áreas naturales protegidas en Misiones-Argentina. El caso etnográfico que en este artículo describimos fue analizado a través de una labor teórico-técnica que nos permitió interpretar los datos relevados durante el prolongado trabajo de campo por etapas que se efectuó en los años 2011, 2012, 2013, 2014 y 2015, con los distintos grupos partícipes de la problemática a tratar: el proyecto de construcción de un camino provincial al interior del lote ocho de la Reserva de Biosfera Yabotí en San Pedro, Misiones-Argentina. Dicho proyecto suscitó un importante conflicto en el que luchan, se involucran e intermedian organizaciones transnacionales, gubernamentales y no gubernamentales, funcionarios, políticos y empresarios.

El trabajo de campo y la participación en el terreno antes mencionada, dio como resultado observaciones, notas de campo y entrevistas tanto en los municipios de San Pedro como en El Soberbio, ambos de la provincia de Misiones. Los datos allí obtenidos nos permitieron no solo definir qué era aquello que estaba en juego, sino también los intereses irreductibles del proyecto de construcción de este controvertido camino y los sesgos de enfoque correspondientes a cada uno de los grupos sociales involucrados (Bourdieu, 1990) en la lucha por generar hegemonía. Es decir, por generar 
una unidad intelectual y moral que abarque a la sociedad entera, a través de la constitución de un «consenso colectivo» entre los grupos implicados.

En términos de Bourdieu (1972, 1990, 1998, 2001) es difícil establecer la existencia de un «campo ecológico» o de algo similar, porque no existe un capital específico en disputa, diferente, a su vez, al capital en juego en el sector económico, político o científico. En otras palabras, no existe una autonomía de «lo ecológico» respecto a la esfera política, científica, y económica. No obstante, el concepto de «figuración» como «...un 'tejido de tensiones', constituido por el entramado de relaciones interdependientes entre personas o grupos» (Elías, 1990: 157) nos lleva a evitar «saltos de gigantes teóricos y enanos empíricos» (Martín, 2008) permitiéndonos analizar la especificidad de los problemas ecológicos y su vinculación con otras esferas locales de actividad, como la política, la economía y las ciencias.

Aunque no haya un "campo ecológico», los agentes implicados en el conflicto del camino del lote 8 están dotados de «habitus», ${ }^{1}$ es decir, reconocen en buena medida las reglas inmanentes del juego, las relaciones de fuerzas, los capitales en disputa (económico, político, o académico), y los fundamentos sobre los cuales basan su fuerza cada uno de los agentes involucrados. Esto lleva a los grupos dominantes a aplicar estrategias que apuntan a la conservación del poder que poseen, mientras que los sectores subalternos intentan subvertir el orden dominante proponiendo una ruptura crítica, ligada a las crisis del momento.

Los grupos dominantes necesitan, entonces, idear justificaciones -o ideologías, en este sentido- que generen una aceptación de su ortodoxia generalizada $y$, en parte, velada. Por lo cual, al observar y describir e interpretar las estrategias desarrolladas por los diferentes sectores, que son conscientes de que los afectados están inmersos en relaciones desiguales de poder, profundizamos el conocimiento acerca de sus dimensiones formales e institucionalizadas, de los procesos sociales y culturales que los modelan (Badaró y Vecchioli, 2009) y de las configuraciones del posible campo que investigamos.

\section{Antecedentes}

A nivel global, hemos realizado un intenso rastreo de autores que desde distintas disciplinas (económicas, humanísticas, naturales, etc.) han tratado temas similares o afines a la problemática que pretendemos abordar. En dicho sondeo, constatamos que

\footnotetext{
${ }^{1}$ En términos de Pierre Bourdieu (1972) el «habitus» se define como «...un sistema de disposiciones durables y transferibles -estructuras estructuradas predispuestas a funcionar como estructuras estructurantes- que integran todas las experiencias pasadas y funcionan en cada momento como matriz estructurante de las percepciones, las apreciaciones y las acciones de los agentes, de cara a una coyuntura o acontecimiento y que él contribuye a producir» (Bourdieu, 1972: 178).
} 
si bien existen análisis que sitúan al turismo en una nueva etapa de capitalización y dependencias (Ribeiro, 2004; Salazar, 2006a; Salazar, 2006b; Belsky, 1999; Wilkinson y Pratiwi, 1995; Escobar, 1998) destacándolo como una oportunidad para nuevas alternativas de desarrollo e integración (Young, 1999; Steel, 2012; Hjalager, 2015; Powell y Ham, 2008; Abínzano, 2000 y 2001) otros consideran que remite a una nueva etapa de modernismo y transformación cultural (Cohen y Avieli, 2002; Cohen 2008; Cohen, 1988; Harkin, 1995; Bruner, 1991; Kraustofl, 2015). Las dimensiones del turismo son varias y el campo científico se ha expedido respecto a ello. Dichas dimensiones incluyen el «turismo cementerio» (Venbrux, 2010), el «turismo cultural» (Cousin, 2006), el «turismo religioso», el «turismo en territorios de gran densidad religiosa» (Guillaumon, 2012), o el «Healthcare tourism» (Jackson y Barber, 2015).A nivel mundial y también provincial- es el «ecoturismo» el más atrayente y extendido (Young, 1999; Chirita y Matei, 2012; Bego y Malltezi, 2011; Powell y Ham, 2008). Esto se debe, en buena medida, a las promesas económicas y ecológicas que este implica, como una actividad basada en el uso sustentable de los ecosistemas locales (Ribeiro, 1995; Cunha, 2005; Aguirre, 2012).

Al igual que en el resto del territorio nacional argentino, la mayor parte del turismo de la provincia de Misiones busca explotar paisajes y elementos típicos de los ecosistemas de la provincia, tales como saltos, selvas, arroyos, entre otros (Turismo Internacional, 2013; MINTUR, 2015; FARN y FVSA, 2011; MERNRyT, 2015). Argentina, como país de economía emergente (FMI, 2015), incrementó en la última década la recepción de turistas, así como su inversión en ese sector, y Misiones al ser la provincia con mayor cantidad de áreas naturales protegidas en el país (SIET, 2015; MERNRyT, 2015; AET, 2013 y 2014) se presenta como un escenario en el que están desarrollándose procesos peculiares.

En relación con los recursos naturales, mientras las investigaciones locales sobre conservación y ecosistemas persiguen en general la preservación de especies puntuales (Paviolo y otros, 2012; Hilgert, 2013; Baldovino et al, 2013; Plací et al, 2003), la incorporación de alternativas a la caza furtiva de animales silvestres (Helou, 2013; Carpinetti, 2013; De Angelo y Di Bitetti, 2012), o el estudio de la gestión de conflictos en torno a la fauna de áreas naturales protegidas (Ferrero, 2008, 2009; Ferrero y Gómez, 2011). Las investigaciones antropológicas estudian en general prácticas económicas y, con mayor frecuencia, retoman los procesos de capitalización rural y agrícola (Baranger, 2008, y Baranger et al, 2008; Bartolomé, 1975, y 1982), los condicionamientos de agencias gubernamentales y no gubernamentales sobre pobladores locales (Bartolomé, 1975, 1982; Bartolomé y Schiavoni, 2001, 2006, 2008, 2009; Ferrero, 2005, 2005b; Ferrero y Gómez, 2011), o los procesos organizativos de poblaciones de frontera (Castiglioni, 2007; Nardi, 2008, 2009; Núñez, 2009; Kraustofl, 2015). Los análisis económicos, por su parte, señalan el papel secundario que desempeña el turismo en Misiones (Freaza, 2002; CAT, 2010; Dieckow y otros, 2012; Freaza y Ramires Hita, 1993). 
No obstante, no encontramos en estas investigaciones referencias específicas a conflictos surgidos en torno a los emprendimientos turísticos entre agentes con significativas diferencias respecto del capital económico y político que poseen, por lo cual las pujas que aquí analizamos, entre los sectores vinculados al gobierno de la provincia, las agencias transnacionales, y los propietarios de lotes que están dentro de las áreas naturales protegidas resultará muy contributivo al campo de estudio por incluir y explicitar el encuentro de las diferentes miradas.

\section{Consideraciones iniciales}

La Reserva de Biosfera Yabotí (en adelante RBY), es intervenida por múltiples agentes mediante un continuo juego de double bind, ${ }^{2}$ es decir, mediante estrategias «a favor»o «en contra» de las propuestas del gobierno de la provincia. Es como si a propósito de un tema arbitrario se cuestionara a la RBY, desde varios frentes, con una interrogación que si es negada es falsa, y si es confirmada, es falsa también. Como si a la RBY se le hiciera la pregunta ¿Es ecológicamente sustentable realizar un camino en el lote $8 ?^{3}-$ cuando la misma reserva se encuentra surcada por centenares de caminos realizados para explotación forestal. Frente a esta pregunta, los ambientalistas, empresarios, ONG, y agencias gubernamentales solo pueden equivocarse, si se atienen a responder con un «a favor» o «en contra». El conflicto por la construcción de un camino que uniría al lote 8 con el Parque Moconá ${ }^{4}$ trasluce la fuerza de los encadenamientos de las jugadas sociales que reúnen a múltiples agentes. Esta trama de licitaciones y contestaciones tiene consecuencias prácticas para las agencias que se alinean como opositoras o como adeptos al proyecto del camino al oficial, lo cual engendra las dos hipótesis que propone este artículo:

1) Las agencias que se alinean como opositoras o solidarias con el camino oficial son parte inseparable de una figuración de dependencias.

2) Las agencias que se alinean como opositoras o solidarias con el camino oficial no se orientan a conservar la dinámica de ecosistemas resguardados.

Ambas consideraciones iniciales están unidas, y la primera presupone a la segunda. Las pruebas de fuerza que continuamente envuelven a guardaparques, ambientalistas, ONG, empresarios y agencias gubernamentales, engendran figuraciones de dependencias que excluyen procesos y agentes vinculados con conflictos ecológicos de

\footnotetext{
2 El concepto «double bind» de Gregory Bateson a propósito de la esquizofrenia, da cuenta de una situación comunicativa que no puede ser resuelta con un sí o un no, por incluir elementos paradojales o contradictorios (Bateson, 1972).

${ }^{3}$ En las consideraciones finales volvemos sobre esta interrogación. El lote 8 es una propiedad privada situada al interior de la RBY, y lindante con el Parque Moconá.

${ }^{4}$ Conflicto que aún no termina de dirimirse.
} 
la RBY. ${ }^{5}$ Esta exclusión se debe al efecto de visión y división que producen las tramas de dependencias sociales permeando reflexiones y sentimientos.

En la lucha por imponer de manera hegemónica la visión que sostiene cada grupo implicado en el conflicto, las distintas partes utilizan todas las herramientas que tienen a su alcance. En términos de Muraca (2010) «...solo habrá hegemonía cuando uno de los grupos sociales en lucha logre consolidar sus intereses corporativos como intereses pertenecientes a la totalidad social, y llevar adelante un ejercicio del poder con el consenso activo de los gobernados» (Muraca, 2010: 78). Esta «...batalla de las ideas» (Balsa, 2006: 20) tiene como contendientes a los agentes especializados en la producción de las ideas y a los aparatos de producción ideológica (como los periódicos provinciales), que actúan dentro de los distintos planos institucionales involucrados en el caso. El conflicto por el camino del lote 8 es un hecho clave ${ }^{6}$ en torno al cual se reúnen múltiples agentes con intereses propios y dispares acerca de la sustentabilidad y el desarrollo. En este conflicto, cada grupo ensaya distintas operaciones básicas para construir la hegemonía necesaria que les permita realizar sus propios proyectos. La lucha aquí está dada a través de quienes intentan presentar los intereses particulares de cada sector como si fuesen intereses generales de todo el colectivo. En una clara operación de «despolitización» de la cuestión, cada sector va a intentar presentar las ideas de los sectores opositores como intereses de grupos marginales, muy alejados de los intereses «generales» de la población (Balsa, 2006).

\section{El camino}

A comienzos del año 2012, el Ministerio de Ecología de la provincia de Misiones había solicitado a sus funcionarios un informe faunístico y florístico vinculado a la posibilidad de crear un camino al interior del Parque Moconá. Los funcionarios encargados de este informe señalaron que, de hacerse, tendría un gran impacto ambiental sobre la flora y fauna local (Primera Edición, 2014). Este informe funcionó como el primer eslabón de una cadena de interdependencias, en el sentido de que sus conclusiones fueron apoyadas por el grupo de guardaparques opositores al camino, pero ignorada por el propio Ministerio de Ecología.

En abril de 2012, el Ministerio de Ecología anunció la primera «Alianza Multicultural Público-Privada del Lote $8{ }_{,}{ }^{7}$ sin consultar con el grupo de guardaparques opositores al camino y sin citar los estudios previos que había solicitado. Dicha «alianza», implicaba

\footnotetext{
${ }^{5}$ Señala Elías a propósito de las pruebas de fuerza «Este es un hecho elemental que se encuentra siempre que los hombres se relacionan o entran en relación entre sí, pero que se suele olvidar en la reflexión acerca de las relaciones humanas» (2008: 86). Quienes no pueden participar de estas pruebas de fuerza, se ven obligados, para existir, a alinearse en una u otra posición que les permita, al menos, entrar en el juego.

${ }^{6}$ Según Geertz (1987) a partir de la descripción de un determinado suceso -pieza de interpretación antropológica- uno puede llegar a abordar enormes complejidades de experiencia social, trazando la curva de un discurso social y fijándolo en una forma susceptible de ser examinada.

${ }^{7}$ Misiones Online, 2014.
} 
además de una redistribución y legalización de la propiedad de la tierra, la realización de un camino que uniera a las comunidades indígenas -y mediante ellas, al lote 692B de Moconá S.A., habilitado para realizar turismo ecológico- con la ruta provincial $N^{\circ} 2$.

Meses después, en Noviembre de 2012, un grupo de guardaparques y ambientalistas comenzaron a exigir nuevos informes sobre el proyecto y a recomendar la consideración de caminos alternativos que ellos mismos proponían. Como consecuencia de tal reclamo, en el año 2013 se produjo una serie de reubicaciones (de lugares de trabajo), amenazas y sumarios gestionados por el propio Ministerio de Ecología a guardaparques opositores al camino.

Durante Octubre de 2014, una fracción de este grupo de guardaparques junto a sectores ambientalistas se asociaron con diputados opositores para gestar una estrategia que obligue a la Cámara de Representantes de la provincia a realizar el tratamiento de la posibilidad de caminos alternativos. Esta estrategia consistió en invitar a diputados opositores, periodistas, y otros actores sociales relevantes a recorrer el sendero Chachí y parte de un tapé (sendero aborigen) que el camino oficial destruiría.

El camino oficial tendría aproximadamente 2 kilómetros o más (como señala la línea naranja oscuro en la ilustración 1), y partiría del enclave turístico de Moconá. Los caminos alternativos propuestos por opositores al camino oficial tendrían entre 10 y 15 kilómetros, y partirían antes del puente -que suele inundarse con lluvias prolongadasaprovechando caminos de obrajes ya abiertos. 


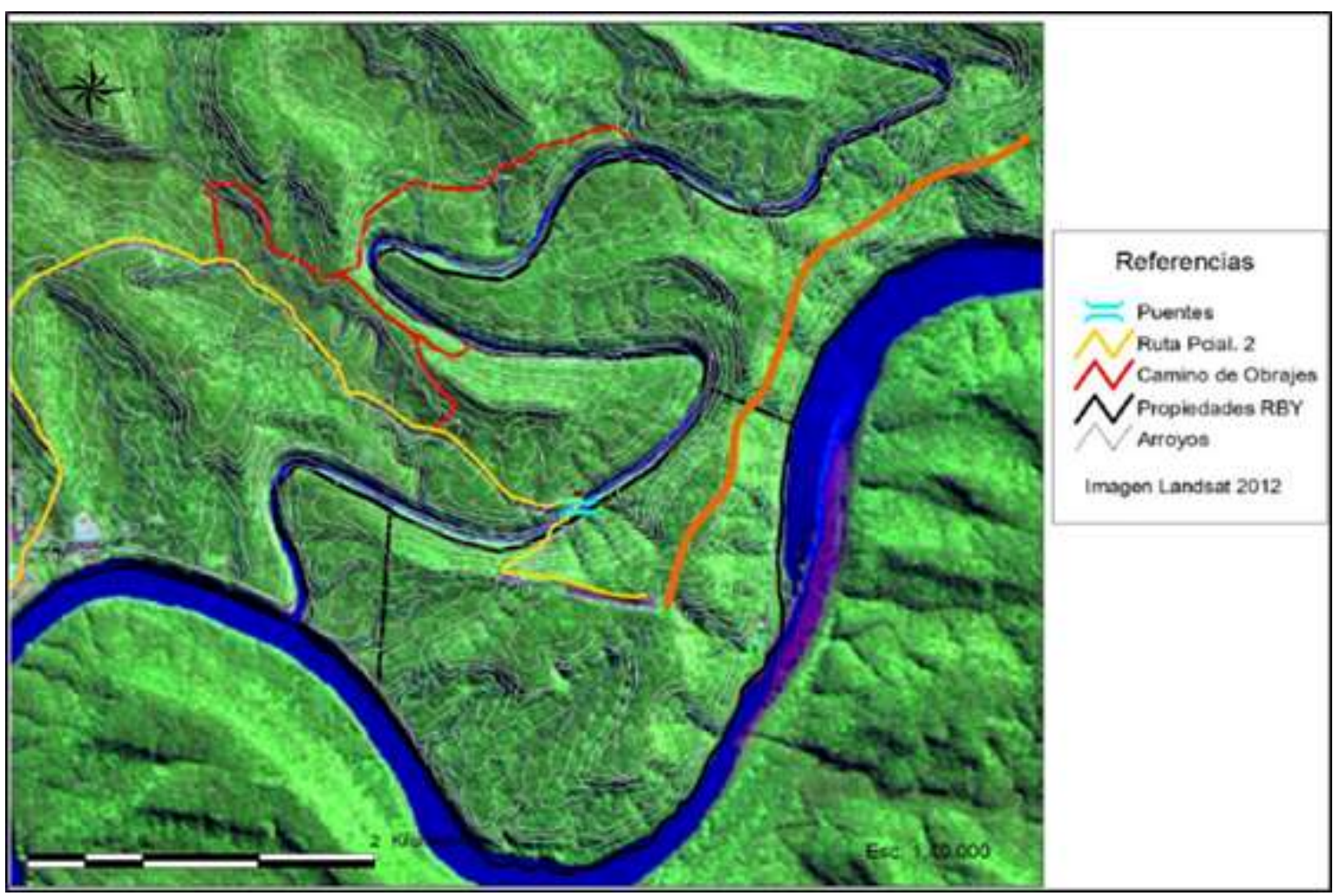

Ilustración 1: Caminos alternativos y camino oficial en naranja oscuro. Fuente AGUMIS

Entre octubre y noviembre de 2014, los diputados y guardaparques ejercieron presión sobre la Cámara de Representantes para que el asunto fuera revisado y se contemplara la propuesta de los caminos alternativos. Después de evitar el tema, alegando que la cuestión no se encontraba en el orden del día, la legislatura recibió finalmente a los guardaparques, en otro momento, en que pudieron exponer su idea del camino alternativo. Después de la exposición realizada, el oficialismo alegó en los medios de comunicación provinciales que los nuevos caminos propuestos eran más largos que el del proyecto inicial, que las comunidades aborígenes estaban de acuerdo con aquella primera propuesta y que de cualquier manera se realizarían los correspondientes estudios de impactos ambientales antes de tomar una decisión, aunque hasta la actualidad no se han expedido acerca de cuál es el camino más conveniente.

\section{Los agentes}

Frente a conflictos como estos, es sumamente necesaria la unión de los distintos agentes debido a que estos, si se encuentran aislados $y$, además, desprovistos simbólicamente, no pueden constituirse en grupos de lucha. Siguiendo a Muraca (2010) la búsqueda de la unidad intelectual y moral, tanto dentro de los grupos dominantes como de los grupos subalternos que tratan de alcanzarla, se realiza a través de un proceso que atraviesa distintas etapas y que utiliza principalmente los principios políticos de «identidad y diferencia», a través de los cuales se puede evaluar el grado 
de homogeneidad, de autoconsciencia y de organización alcanzado por los diversos grupos sociales en lucha.

A través de diferentes reclamos, sectores tan diversos de la sociedad como los que aquí participan (guardaparques, ONG, partidos opositores, comunidades indígenas, y propietarios de tierras dentro de la RBY) comienzan a sentir que tienen cierta comunidad de intereses y es ahí donde el pensamiento hegemónico trasciende los límites de lo meramente político-económico, transformándose en una problemática cultural (Muraca, 2010: 82). Para conquistar el apoyo de los grupos subordinados (guardaparques ambientalistas, comunidades indígenas, y científicos de las ciencias sociales y naturales), los sectores dominantes intentan convencer a las masas de que sus propios intereses sectoriales representan el interés más general, imponiendo en su discurso las «funciones universalistas» de su proyecto. Dicho interés está centrado en que estos grupos (ONG trasnacionales, gobiernos locales, Ministerio de Ecología, y propietarios de lotes internos) cumplen los roles más influyentes en las distintas esferas de la vida social y poseen grandes responsabilidades y un importante capital que los posiciona por sobre los demás ciudadanos pudiendo tomar decisiones cruciales, ya sea como dirigentes, decisores, o custodios de los intereses de determinados sectores de poder, que afectan a los grupos subalternos (Shore, 2009).

Guardaparques y ambientalistas: Los guardaparques involucrados con la gestión de caminos alternativos están vinculados a AGuMIS y AMIRBY. AGuMIS (Asociación de Guardaparques de Misiones) creada en los últimos años, nuclea a guardaparques con un enfoque crítico sobre la gestión oficial de las áreas naturales protegidas en Misiones. Algunos de los guardaparques que formaban parte en algún momento de AMIRBY (Área de Manejo Integral de la RBY, dependiente del Ministerio de Ecología) son parte fundamental de esta organización. Los objetivos de AMIRBY, creada durante los años 2006 y 2007 con el aval de Unesco, tenían que ver con la producción de escenarios participativos para la resolución de conflictos ambientales en la RBY. En la práctica, AMIRBY ya fue desmantelada por la gestión oficial, que derivó el tratamiento de conflictos ambientales a consultores particulares, tal como sucede en la actualidad con el caso del camino del lote 8.

Los objetivos de AGuMIS, más allá de las peculiaridades legales y organizativas, tienen algo en común con los de AMIRBY. Por ejemplo, uno de sus objetivos principales es "generar un acercamiento y poder dialogar con los funcionarios, con el objetivo de comenzar un proceso constructivo justo y evitar que se genere el actual distanciamiento entre las autoridades y los trabajadores» (infoberaweb, 2012) aunque orientados a temáticas más ligadas a problemas laborales de los guardaparques.

También apoyaron la realización y análisis de caminos alternativos, así como la reorganización de AMIRBY, la Fundación Vida Silvestre (FVSA), Conservación Argentina, Centro de Investigaciones del Bosque Atlántico (CeIBA), Aves Argentinas-Asociación Ornitológica Del Plata, Asociación para la Conservación y el Estudio de la Naturaleza 
(ACEN), «bancodebosques.org-bosques para todos», y «Fundación huellas para un futuro», mediante un «documento de posición» (FVSA y otros, 2014).

Los funcionarios oficialistas y opositores: Los cuatro diputados presentes en el recorrido del sendero Chachí y del tapé aborigen representaban a diferentes fracciones políticas, UCR (Unión Cívica Radical), PAyS-NE (Partido Agrario y Social - Nuevo Encuentro) y FPV (Frente Provincial para la Victoria), además de dos concejales de El Soberbio y periodistas de medios provinciales. En este caso, se trataba de funcionarios temporalmente alineados con la oposición al gobierno provincial. El objetivo del recorrido de los senderos era que «comprobasen» ellos mismos la destrucción de ecosistemas que generaría un camino en esa zona y que ejercieran presión para que el tema fuese tratado en la legislatura. Los diputados forman parte de la estructura política gubernamental de la provincia de Misiones, donde se dirimen usualmente los asuntos de mayor interés público. ${ }^{8}$ Tanto diputados oficialistas como opositores suelen acusarse mutuamente de utilizar el poder de las instituciones políticas para aumentar sus beneficios personales. ${ }^{9}$

Comunidades o aldeas aborígenes: Las comunidades Tekoa Yma, Kapi i Ivate, e Itao Miri son comunidades aborígenes asentadas dentro de la RBY junto a otras comunidades. Durante el año 2014, por medio de un acuerdo múltiple llamado oficialmente «Alianza Multicultural Público-Privada» (Misiones Online, 2014), estas aldeas lograron regularizar su tenencia de tierras después de más de 20 años de disputas con los propietarios privados y las agencias gubernamentales. El conflicto del lote 8 dividió también a todas las comunidades aborígenes ligadas a la RBY, pues fue necesario que la mayoría de las comunidades y el EMiPA (Equipo Misiones de Pastoral Aborigen) reunidas en el Aty Ñeychyro realizado en Tekoa Mbokajaty de San Ignacio apoyaran la realización del camino del lote 8 tal como lo plantearon inicialmente las tres comunidades involucradas. A pesar de la presión, en la actualidad, tanto guardaparques, ambientalistas como diputados opositores intentan convencer a las comunidades y a EMiPA de que desistan del camino oficial.

Agencias gubernamentales y transnacionales: La Alianza del Lote 8 estuvo integrada por el Gobierno de Misiones a través del Ministerio de Ecología, la organización británica World Land Trust (WLT) asociada en Argentina con la Fundación Naturaleza para el Futuro (FUNAFU), las Comunidades Mbya Guaraní (Tekoa Yma, Kapi'i Yvate e Itao Miri) y la empresa Moconá S.A. -titulares registrales del Lote 8.

\footnotetext{
${ }^{8}$ Como señala Wright Mills «A medida que es más estrecho el círculo de los que deciden y cuando los medios de decisión están centralizados y las consecuencias de las decisiones son enormes, el curso de los grandes acontecimientos estriba en las decisiones de círculos que pueden determinarse» (1987: 28).

${ }^{9}$ Esta es una acusación frecuente también en etapas anteriores al desarrollo del Estado moderno, como señala Bourdieu et al. a propósito de los principados italianos «El poder personal (que puede no tener nada de absoluto) es la apropiación privada del poder público, el ejercicio privado de ese poder» (2005: 59).
} 
Las agencias no gubernamentales como las agencias transnacionales conforman con las agencias gubernamentales provinciales parte de la estructura institucional local en la que se disputa y se concentra la mayor parte del capital político y económico.

El acuerdo implicó, en síntesis, la compra del lote 8 con fondos de la WLT, la anexión de este lote de 4.000 ha a la RBY y la producción de varias subdivisiones y nuevos derechos y reglas para los propietarios. El resultado de la subdivisión de tierras fue 3.203,27 ha propiedad de las aldeas indígenas, 202,30 ha de Moconá S.A., 10,35 ha de FUNAFU y 483,07 ha en condominio entre comunidades indígenas y la FUNAFU, como puede verse en la Ilustración 2.

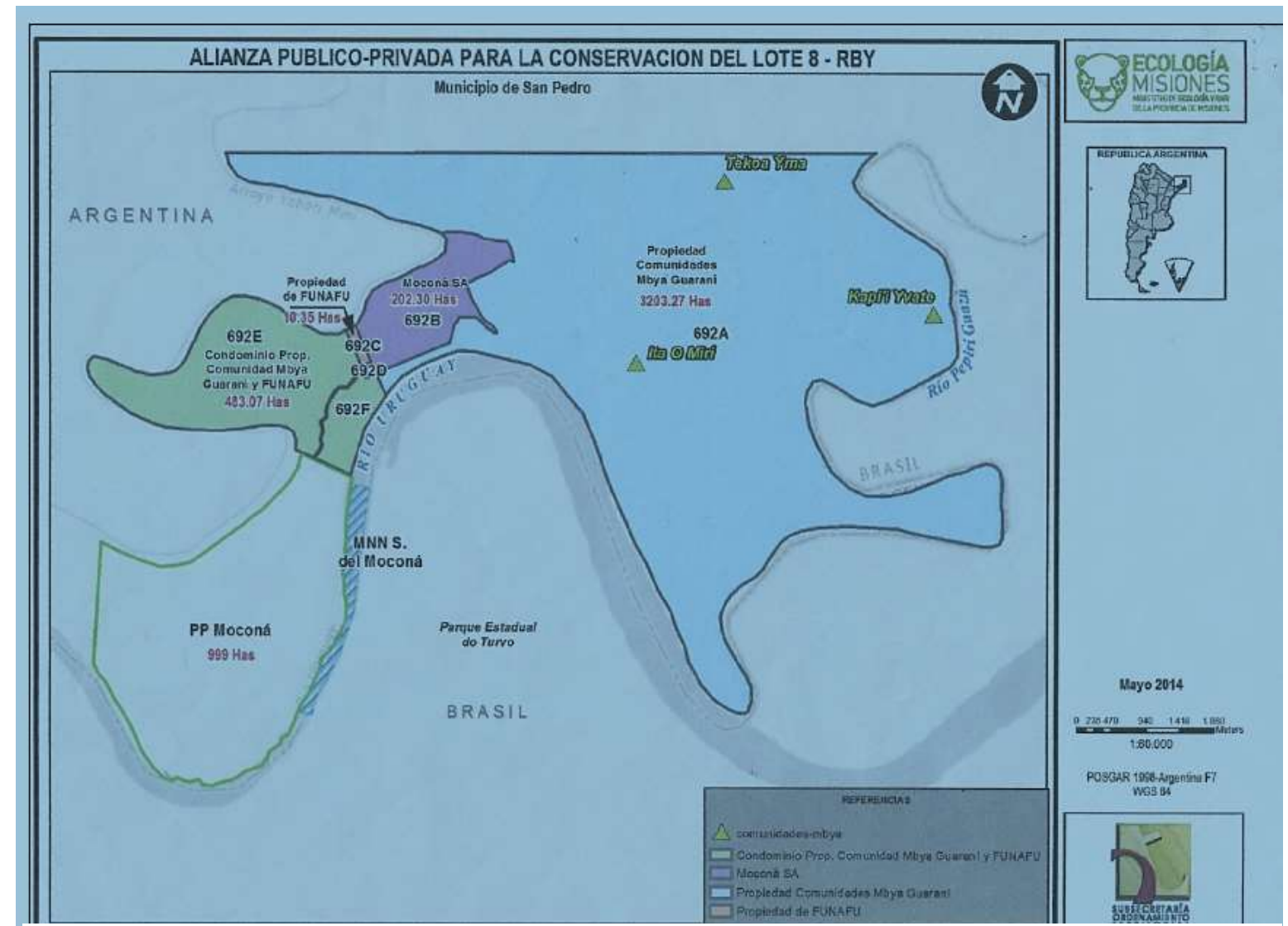

Ilustración 2. Distribución de tierras del acuerdo múltiple. Fuente: Subsecretaria de Ordenamiento Territorial de la Provincia de Misiones.

\section{Consideraciones finales: figuraciones y visiones}

En la actualidad, la clave estructural de los grupos de poder reside en el sector político, por ello, pedir ayuda y adhesión a aquellas áreas que pueden apoyar el proyecto de cada grupo, a pesar de la decadencia de la política como debate auténtico y público de soluciones, no solo es válido, sino también necesario, porque el gobierno y los negocios se encuentran unidos intrincada y profundamente, ya que un aspecto 
clave para la construcción de dicho poder, reside en el sector económico (Wright Mills, 1987).

Un camino que atraviese el parque Moconá, bordeando el río Uruguay hacia el interior de la selva de la RBY, que culmine en hoteles o cabañas con acceso a senderos agrestes, rodeados de la fauna silvestre y paisajes selváticos con miles de ha de selva como horizonte se traduce en cúmulos de beneficios económicos a corto plazo. El acuerdo del lote 8 con la cesión y redistribución de tierras ¿podría haberse llevado a cabo si no tuviera como exigencia un camino y acuerdos para instalaciones y actividades ligadas al turismo? Este es uno de los puntos centrales de la disputa que ambientalistas, opositores y oficialistas evitan discutir -la ruta asfaltada que desde hace varios años llega al parque Moconá, no despertó ninguna acción por parte de ambientalistas y diputados opositores. No es la fragilidad de los ecosistemas lo que licita la acción de ambientalistas y no es el bienestar de las comunidades aborígenes lo que mueve al gobierno provincial. Se trata de quiénes están «en contra» y quiénes están «a favor» de una redistribución "oficial» de la selva, lista a ser reconvertida en recurso turístico y económico.

Esta disyuntiva entre un camino oficial o un camino alternativo, de aparente oposición, guarda en realidad un fondo común: ambas posiciones están de acuerdo en enfocar de cierta manera el problema del camino del lote 8. Como sugerimos en las consideraciones iniciales: (1) las agencias que se alinean como opositoras o solidarias con el camino oficial son parte inseparable de una figuración de dependencias; 2) Las agencias que se alinean como opositoras o solidarias con el camino oficial no se orientan a conservar la dinámica de ecosistemas resguardados.

1) El proceso de los acuerdos sobre el lote 8 sigue fundamentalmente el ritmo de las oposiciones e interdependencias entre jugadas oficialistas y opositoras, pujas que se dirimen en la Legislatura de Misiones. Es decir, las intervenciones sobre la RBY, aunque sean mediatizadas por AMIRBY o la FUNAFU y algunos funcionarios particulares, sigue el vaivén de las interdependencias entre bloques de la cámara de representantes de Misiones.

Fuera de estas interdependencias quedan las agencias gubernamentales y no gubernamentales de los municipios de San Pedro y El Soberbio, las colonias rurales, los comerciantes y empresarios locales ligados al turismo y cualquier otro grupo de la sociedad civil. Las comunidades aborígenes solo son consultadas para apoyar o denunciar una $\mathrm{u}$ otra propuesta ya establecida, ${ }^{10}$ al igual que los investigadores tanto de ciencias naturales como sociales, y las ONG ambientalistas nacionales y provinciales.

Las demandas de estos sectores subalternos, antes de ser internalizadas, siempre son sometidas tal como señala Balsa (2006) a procesos de negación, desvalorización y

\footnotetext{
10 Estas pujas entre «pretendientes» y «dominantes», como señala Bourdieu (1990) constituye una invariante de los campos. Es decir en todo entramado social, se diputa algo. La pregunta es, ¿Qué formas y consecuencias adquieren estas disputas?
} 
utopización dándoles un sentido negativo, afirmando que son irrealizables, para luego darles lugar a una cierta aceptación limitada y pasiva, en un proceso de transformación «desde lo alto» en el que si bien se recupera una pequeña parte de las demandas «de abajo», se les quita iniciativa política autónoma.

2) a. Las intervenciones producidas por medio de la FUNAFU, WLT y el Ministerio de Ecología, no pueden conservar los ecosistemas y resguardar el bienestar de las poblaciones aborígenes. Del mismo modo, las intervenciones mediatizadas por diputados, AMIRBY, AGUMIS y ambientalistas, no pueden conservar los ecosistemas y resguardar el bienestar de las poblaciones locales. El efecto de cierre que generan las interdependencias prácticas entre cualquier tipo de agencias alineadas en la dicotomía de oficialistas u opositores, deja afuera la posibilidad de dimensionar objetivamente los problemas de conservación y política que plantea el camino del lote 8 , un camino de entre 2 y $15 \mathrm{~km}$ aproximadamente según una u otra propuesta. Prueba de esto son los más de $1.000 \mathrm{~km}$ de caminos que atraviesan el interior de la RBY, conectando a decenas de lotes privados (cada uno con más de 10.000 ha en promedio) con rutas nacionales y provinciales. Por esos caminos se realiza la explotación forestal y la caza furtiva con escaso control, ambas actividades de gran impacto ecológico. ${ }^{11}$ Pero estos caminos, que ni siquiera aparecen en los mapas oficiales y públicos del Ministerio de Ecología, jamás despertaron ninguna movilización ni de guardaparques, ni de diputados, ni de agencias transnacionales, ni gubernamentales ligadas a la protección de ecosistemas selváticos.

2) b. La distribución de poderes que organiza la política hegemónica de la provincia relega a las ciencias sociales y naturales a un lugar deplorable. En el caso del camino del lote 8, los investigadores solo son llamados a posicionarse a favor o en contra, porque los problemas ya fueron planteados en la cámara de representantes de Misiones. Los científicos solo pueden ser consultados para dirimir las luchas acerca de lo que la naturaleza quiere decir, sin interrogarse sobre la política de cada naturaleza particular. ${ }^{12}$ Los dictámenes científicos en el área de la conservación, la mayoría de las veces omiten el análisis científico de problemas políticos, sirviendo con esta negligencia

\footnotetext{
11 Tampoco los planes de manejo elaborados por ingenieros forestales para propietarios privados, y aprobados por el Ministerio de Ecología, encuentran gran resistencia, al igual que la construcción de un restaurante y una pasarela en el mismo Parque Moconá, durante el 2013, y a menos de $200 \mathrm{~m}$ de donde se realizaría el camino oficial.

12 Los científicos son los únicos que -habiendo salido de la cámara de las representaciones, de las candentes pujas de valores y, en suma, del espacio público-, pueden ascender a la fría y muda cámara de la naturaleza y registrar lo que ella dice. Para volver finalmente luego a la oscuridad de las ficciones y al vocerío de la política, y poner fin con autoridad a las obtusas discusiones de quienes siguen en las sombras. La ironía de Latour (2004), su lectura del mito de la caverna y su crítica a las relaciones primigenias entre ciencia y política es una crítica al olvido de las interrogaciones científicas de problemas políticos.
} 
a la instauración de problemas -fuera de lugar- que solo tienen sentido en el marco de las tensiones entre agencias dominantes, provinciales, nacionales y transnacionales. ${ }^{13}$

\section{Bibliografía}

ABÍNZANO Roberto. (2000). Antropología, derechos humanos y globalización: algunas reflexiones. Avá Revista de antropología. Nro. 2 pp. 21 a 41.

ABÍNZANO Roberto. (2001). Integración regional fronteriza «desde abajo». Nuevos sujetos colectivos, ¿nuevos poderes? Estudios Regionales. Año 9. 17 pp. 9-29.

AGUIRRE Alejandrina. (2012). Tres parques seguros para acampar. Contenido. Vol. 591 pp. 92-99.

BADARÓ Máximo y VECCHIOLI Virginia. (2009). Algunos dilemas y desafíos de una antropología de las elites. Etnografías contemporáneas. Buenos Aires.

BALDOVINO María Celia, JANSON Charles y DI BITETTI, Mario. (2013). La demografía de los monos caí (cebus [apella] nigritus) en el parque nacional iguazú: ciclo de vida de los grupos. Jornadas Científico Tecnológicas 40 Aniversario de la Universidad Nacional de Misiones. Editorial Universitaria. Posadas.

BALSA, Javier. (2006). Las tres lógicas de la construcción de hegemonía. Revista Theomai $\mathrm{N}^{\circ} 14,2^{\circ}$ semestre/06.

BARANGER Denis, NIÑO Fernanda y SIMONETTI Eduardo (2008). Construcción de una tipología de los ocupantes de tierras privadas en Misiones. En Bartolomé L. y Schiavoni G. Desarrollo y estudios rurales en Misiones. Ciccus. Posadas.

BARANGER Denis. (2008). La construcción del campesinado en Misiones: de las Ligas Agrarias a los «sin tierra». En Schiavoni, G. (Comp.) Campesinos y agricultores familiares. La cuestión agraria en Misiones a fines del siglo XX. Ciccus. Misiones.

BARTOLOMÉ Leopoldo y SCHIAVONI Gabriela (2008). Desarrollo rural y estudios rurales en Misiones. Buenos Aires: Ciccus.

BARTOLOMÉ Leopoldo (1982). Base Social e Ideología en las Movilizaciones Agraristas en Misiones entre 1971 y 1975. En Desarrollo Económico. Vol., 22: 85, pp., 25-56.

BARTOLOMÉ Leopoldo. (1975). Colonos, Plantadores y Agroindustrias. La Explotación Agrícola Familiar en el sudeste de Misiones. Desarrollo Económico. Vol., 15:58, pp., 239-264.

BATESON Gregory. (1972). Steps to an Ecology of Mind: Collected Essays in Anthropology, Psychiatry, Evolution, and Epistemology. New Jersey: Jason Aronson Inc.

BEGO Ferdinand MALLTEZI Jamarber. (2011). Ecotourism opportunities and challenges in Butrint, Albania, a Unique UNESCO and Ramsar site. Journal of Coastal Research. Issue SPEC. Nro., 61, pp., 150-157.

\footnotetext{
${ }^{13}$ Como remarca Bourdieu, cuando las ciencias intervienen en el campo político se vuelven «... objeto de una grandísima solicitud, tanto positiva y, a menudo, muy lucrativa, material y simbólicamente ...» (2003: 9).
} 
BELSKY Jill. (1999). Misrepresenting communities: the politics of community-based rural ecotourism in Gales Point Manatee, Belize. Rural Sociology. Vol. 64 pp. 641-66.

BOURDIEU Pierre, CHAMPAGNE Patrick, CHRISTIN Olivier, EYAL Gil, POUPEAU Franck y WACQUANT Loïc. (2005). El misterio del ministerio. Barcelona: Gedisa.

BOURDIEU Pierre. (2003). El oficio del científico. Barcelona: Anagrama.

BOURDIEU Pierre. (2001). Las estructuras sociales de la economía. Buenos Aires: Ediciones Manantial.

BOURDIEU Pierre. (1998). La distinción. Criterios y bases sociales del gusto. Madrid: Taurus.

BOURDIEU Pierre. Sociología y cultura. (1990). México D.F.: Grijalbo.

BOURDIEU Pierre. (1972). Esquisse d'une theorie de la pratique. Paris: Droz.

BOURDIEU Pierre. Sociología y cultura. (1990). México D.F.:

Grijalbo.

BRUNER Edward M. (1991). Transformation of self in tourism. Annals Of Tourism Research. Vol. 18 pp. 238-50.

CARPINETTI Bruno (2013). La política del «perro del hortelano». Control de la caza furtiva y manejo de especies exóticas en el refugio de vida silvestre Bahía de Samborombón. Ieras Jornadas de Conservación y Comunidades en el Cono Sur. Universidad nacional de Misiones.

CASTIGLIONI Guillermo. (2007). Tabacaleros no anotados: una familia en el limbo. En Baranger D. (comp.) Tabaco y agrotóxicos. Un estudio sobre productores de Misiones. Misiones: Editorial Universitaria.

CHIRITA Viorel. MATEI Daniela. (2012). The relational articulation between communities and protected areas in the Dorna-Călimani mountain area (the Eastern Carpathians of Romania. 12th International Multidisciplinary Scientific GeoConference and EXPO - Modern Management of Mine Producing, Geology and Environmental Protection, SGEM. Disponible en http://www.scopus.com/inward/record.url?eid=2-s2.084890703916\&partnerID $=40 \&$ md5 $=c 7$ e7de7b5f9348a57d5b240feddfdd19. Fecha de acceso: Varna.

COHEN Erik y NIR Avieli. (2002). Food in tourism: Attraction and Impediment. Annals of Tourism Research. Vol. 31: 4 pp. 755-778.

COHEN Erik. (1988). "Authenticity and commoditization in tourism». Annals Of Tourism Research. Vol., 15, pp., 371- 86.

COHEN Erik. (2008). The Changing Faces of Contemporary Tourism. Society. Vol 45: 4 pp. 330-333.

COUSIN Saskia. (2006). Le «tourisme culturel», un lieu commun ambivalent. Anthropologie et Sociétés. Vol., 30 2. pp. 153-173.

CUNHA LUSTOSA Isis María. (2005). RPPN, eco turismo, populações tradicionais e/ou residentes: dilemas de uma política de áreas particulares protegidas» 
. Boletim Goiano de Geografia. Vol., 25:1-2, pp., 61-74.

DE ANGELO C., PAVIOLO A., DI BITETTI Mario (2012). Diferentes aproximaciones de modelos de hábitat para el estudio y manejo del jaguar (Panthera onca) en el Bosque Atlántico del Alto Paraná. X Congreso Internacional de Manejo de Fauna Silvestre en la Amazonía y Latinoamérica. Salta.

DIECKOW Liliana. BRONDANI, Nancy. A.CÁCERES Angelina. N. (2012). Los Impactos Económicos de las Políticas Turísticas: Desarrollo Local o Enclaves Turísticos El Caso Paradigmático De Santa Ana, Misiones, Argentina. Palermo Business Review. Special Issue pp. 149-162.

ELÍAS Norbert. (1990). La sociedad de los individuos. Ediciones Península. Barcelona.

ELÍAS Norbert. (2008). Sociología fundamental. Gedisa. Barcelona.

ESCOBAR Arturo. (1998). La invención del Tercer Mundo. Construcción y deconstrucción del desarrollo. Norma. Bogotá.

FERRERO Brián (2009). Caza, masculinidad y ambientalismo. Transformaciones en la práctica cinegética en el noreste argentino. Suplemento Antropológico. Vol. 43 pp. 299-321.

FERRERO Brián. (2005). "La ecología de los colonos». Búsquedas de inclusión en un territorio ambientalista. En Anuario de Estudios en Antropología Social. CAS-IDES pp. 187-197. Buenos Aires.

FERRERO Brián. (2008). Más allá del dualismo naturaleza-sociedad: poblaciones locales y Áreas Naturales Protegidas en Misiones. En Bartolomé L. y Schiavoni G. (Comps.), Desarrollo y Estudios rurales en Misiones. Ciccus. Buenos Aires.

FREAZA Miguel Ángel. (2002). Economía de misiones: aspectos y actividades relevantes. Editorial Universitaria. Misiones.

FREAZA Miguel Ángel. y RAMIREZ HITA Susana. (1993). La Economía de Misiones y Su Inserción en el Contexto Regional: Propuesta Metodológica para la Medición de Sus Efectos. Editorial Universitaria. Misiones.

GEERTZ Clifford. (1987). La interpretación de las culturas. Editorial GEDISA. México

GÓMEZ Elías y FERRERO Brián. (2011). Estilos de desarrollo sustentable en el norte de Misiones. Cadernos de campo-revista dos alunos de pós-graduação em antropologia social da USP. Vol. 20: 20 pp. 125-141.

GUILLAUMON Siegrid. (2012). Turismo em territórios de grande densidade religiosa. Organizações \& Sociedade. Vol. 19: 63 pp. 679-696.

HARKIN Michael. (1995). Modernist anthropology and tourism of the authentic. Annals Of Tourism Research. Vol. 25 pp. 650-70.

HELOU Marcia. (2013). Experiencia en extensión de la cría de pacas y agutíes a productores misioneros. Ieras Jornadas de Conservación y Comunidades en el Cono Sur. Participación, alianzas y conflictos en la conservación de la naturaleza. Posadas 
HILGERT Norma. (2013). La conservación cultural y ambiental, dos caras de la misma moneda. En leras Jornadas de Conservación y Comunidades en el Cono Sur. Universidad Nacional de Misiones.

HJALAGER Anne-Mette. (2015). 100 Innovations That Transformed Tourism». Journal of Travel Research. Vol. 54:1 pp. 3-21.

JACKSON Leonard A., S. BARBER Diana. (2015). Ethical and sustainable healthcare tourism development: A primer. Tourism and Hospitality Research. Vol. 15: 99 pp. 16-26.

KRAUTSTOFL María Elena. (2015). Territorio de fronteras y espacio de cuerpo/mujer. Peregrinación transnacional de las paseras entre Posadas (Argentina) y Encarnación (Paraguay). La Rivada. № 3 pp. 1-16.

LATOUR Bruno. (2004). Políticas da natureza. Como fazer ciência na democracia. Sao Paulo: EDUSe..

MARTIN Criado Enrique. (2008). El concepto de campo como herramienta metodológica. Revista Española de Investigaciones Sociológicas (Reis). Nro. 123 pp. 11-33.

MURACA Matías. (2010). Hegemonía, dialéctica de la diferencia. En: Rinesi Eduardo, Vommaro Gabriel, y Muraca Matías. (comps.) Si este no es el pueblo. Hegemonía, populismo y democracia en Argentina. pp. 77-89. Buenos Aires: UNGS.

NARDI María. (2008). «Organizaciones y desarrollo rural en el nordeste de la provincia de Misiones. Una perspectiva territorial crítica». Tesis de Maestría en Economía Agraria. Facultad de Agronomía de la UBA. Mimeo.

NúÑEZ Ana. (2009). «La Dimensión Política del Desarrollo Local. Posibilidades y controversias». Cuaderno de Investigación del PODECI. Secretaría de Investigación y Postgrado-UNaM.

PAVIOLO Agustín, DE ANGELO Carlos, CRUZ Paula, PIZZIO Esteban, ZAMUDIO Fernando y DI BITETTI Mario. (2012). «Mortalidad de jaguares (panthera onca) inducida por humanos en el bosque atlántico de argentina ¿eliminación por conflictos con el ganado, caza para la obtención de pieles o consecuencia de la caza indiscriminada?». X Congreso Internacional de Manejo de Fauna Silvestre en la Amazonía y Latinoamérica. Salta.

PLACÍ Guillermo y DI BITETTI Mario (2003). Situación ambiental en la ecorregión del Bosque Atlántico del Alto Paraná (selva paranaense). En Di Bitetti, M., G. Placci y L. A. Dietz Una visión de biodiversidad para la Ecorregión del Bosque Atlántico del Alto Paraná: Diseño de un paisaje para la conservación de la biodiversidad y prioridades para las acciones de conservación. World Wildlife Fund. Washington DC.

POWELL Robert B., HAM Sam.H. (2008) Can ecotourism interpretation really lead to pro-conservation knowledge, attitudes and behaviour? Evidence from the Galapagos Islands. Journal of Sustainable Tourism. Vol. 16:4 pp. 467-489. 
RIBEIRO Gustavo Lins. (2004) Globalización y diversidad cultural: una mirada desde América Latina. Ramón Pajuelo, Pablo Sandoval (comp.). Instituto de Estudios Peruanos. Lima.

RIBEIRO Gustavo Lins. (1995). Transnational Capitalism and Hydropolitics in Argentina: The Yacyretá High Dam. The Hispanic American Historical Review. Vol., 75:2, pp., 314-315.

SALAZAR Noel B. (2006) Antropología del turismo en países en desarrollo: análisis crítico de las culturas, poderes e identidades generados por el turismo. Tabula Rasa. No 5 pp. 99-128.

SALAZAR Noel B. (2006) Construyendo una «cultura de la paz» a traves del turismo: notas y preguntas reflexivas y analíticas. Universitas Humanistica. No 62 pp. 319533.

SHORE Cris. (2009) Hacia una antropología de las elites. En: Etnografías contemporáneas. pp. 23-46. Ed. Universidad Nacional de San Martín. Buenos Aires.

STEEL Griet. (2012) Local encounters with globetrotters: Tourism's Potential for Street Vendors in Cusco, Peru. Annals of Tourism Research. Vol. 39:2 pp. 601-619.

VENBRUX Eric. (2010) Cemetery tourism: coming to terms with death?. La Ricerca Folklorica. № 61 pp. 41-49.

WILKINSON Paul.F, PRATIWI Wiwik. (1995) Gender and tourism in an Indonesian village. Annals Of Tourism Research. Vol. 22 pp. 283-99.

WRIGHT Mills. (1987) La élite del poder. Fondo de cultura económica. México DF.

YOUNG Emily.H. (1999) Balancing conservation with development in small-scale fisheries: Is eco-tourism an empty promise. Human Ecology. Vol., 27, pp., 581-620.

\section{Fuentes}

ABM. 2010. Asociación Bosque Modelo. Plan estratégico de desarrollo sustentable del municipio de San Pedro. Estudio 1.EE.375. Inédito. Misiones

AET.1996 hasta 2015 (varios ejemplares). Anuario estadístico de turismo. Ministerio de Turismo de la Nacion Argentina. En http://desarrolloturistico.gob.ar/anuariosestadisticos.

CAT. 2010. Cámara Argentina de Turismo. Informe económico cuatrimestral sobre la actividad de viajes y turismo. En http://www.hmiargentina.com/archivos/1288720848.pdf

EL PARANAENSE. 2014. http://elparanaense.com.ar/camino-por-el-parque-moconaahora-en-diputados/. Revisado 23/03/2015

FARN y FVSA. 2011. Diagnóstico para la creación de un Mecanismo de pago por servicios ambientales: Bosque Atlántico del Alto Paraná, Misiones, Argentina. En www.farn.org.ar/newsite/.../PSA_IBAAP_28102011.pdf . Revisado 12/10/2012

FMI. $2015 . \quad$ http://es.scribd.com/doc/7882374/IMF-Classification-ofCountries\#scribd.Revisado 15/02/2015. 
FVSA Y OTROS. 2014. Documento de Posición. Inédito.

INFOBERAWEB. 2012. http://www.infoberaweb.com.ar/2012/03/15/la-agumis-apoya-elreclamo-y-medidas-de-fuerza-de-los-guardaparques/. Revisado 20/02/2015.

INFOBERAWEB.2012. http://www.infoberaweb.com.ar/2012/03/15/la-AGuMIS-apoya-elreclamo-y-medidas-de-fuerza-de-los-guardaparques/. Revisado 15/02/2014

MERNRyT. 2005. Ministerio de Ecología y Recursos Naturales Renovables .Revisión De La Reserva De Biosfera Yaboty. Período 1995 - 2005. (Documento de Discusión). Documento inédito. Misiones

MERNRyT. 2015. http://www.ecologia.misiones.gov.ar/ecoweb/index.php

MINTUR. 2015. Ministerio de Turismo de la Nación Argentina. En http://www.turismo.gov.ar/.

MISIONES ONLINE 2014. http://misionesonline.net/2014/05/30/yaboti-presentaron-enla-legislatura-la-alianza-del-lote-8-como-el-primer-acuerdo-de-gobernabilidadambiental-multicultural-de-misiones/ . Revisado 13/12/2015.

MISIONES ONLINE. 2015. http://misionesonline.net/2014/05/30/yaboti-presentaronen-la-legislatura-la-alianza-del-lote-8-como-el-primer-acuerdo-degobernabilidad-ambiental-multicultural-de-misiones/. Revisado 23/01/2015 PRIMERA EDICIÓN. 2012. http://www.primeraedicionweb.com.ar/nota/impreso/93840/guardaparquesdenuncian-negociados-turisticos-en-mocona.html. Revisado 20/02/2015.

PRIMERA

EDICION.2014.

http://www.primeraedicionweb.com.ar/nota/impreso/130934/lote-8-ecologia26ldquo3Bcajoneo26rdquo3B-un-informe-negativo-a-camino-oficial-en-elmocona.html. Revisado 15/02/2014

SAyDS. 2015. Secretaría de Ambiente y Desarrollo Sustentable. http://www.ambiente.gov.ar/?idseccion=115.

SIET, 2015. Sistema de información y estadística turística. Ministerio de Turismo de la Nación Argentina. En http://siet.desarrolloturistico.gov.ar/.

TERRITORIO

DIGITAL.

2012.

En http://www.territoriodigital.com/nota3.aspx?c=1485725360801098\&fb_action_ids $=277582232344260 \& \mathrm{fb} \_a c t i o n \_t y p e s=$ og.recommends\&fb_ref $=$.UKFD9kIW_II.like $\& \mathrm{fb} \_$source=aggregation \&fb_aggregation_id=288381481237582 . Revisado $13 / 12 / 2015$.

TERRITORIO

DIGITAL.

2013. http://www.territoriodigital.com/nota3.aspx?c=2554191048901341. Revisado $15 / 02 / 2014$

TURISMO INTERNACIONAL. 2013. Turismo internacional, todas las vías. Subsecretaría de Desarrollo Turístico-Dirección Nacional de Desarrollo Turístico. En http://www.desarrolloturistico.gov.ar/ 